\title{
O ENFRENTAMENTO EMOCIONAL DO PROFISSIONAL DE ENFERMAGEM \\ NA ASSISTÊNCIA AO PACIENTE NO PROCESSO DA TERMINALIDADE DA VIDA
}

\author{
Danielle de Souza Santa Rosa*, Selma Alelvia Couto* \\ Autora correspondente: Danielle de Souza Santa Rosa - E-mail: selmaenfe@hotmail.com \\ Graduada no Curso Enfermagem da Universidade Salvador/Bahia
}

Resumo

Trata-se de uma revisão bibliográfica, descritiva, de natureza qualitativa, cujos objetivos foram: Compreender os sentimentos dos profissionais de enfermagem frente ao paciente enfermo no processo da terminalidade da vida; Discutir os motivos que levam estes a adotar determinadas posturas (de afastamento ou aproximação) diante desta situação e discutir as implicações do preparo ou despreparo deste profissional na assistência ao paciente no processo de morte. Utilizou-se a base de dados do Lilacs e Bireme, considerando as publicações dos anos 2002-2012. Após análise dos artigos surgiram três categorias: Sentimentos dos profissionais de enfermagem frente ao paciente enfermo no processo da terminalidade; Posturas dos profissionais de enfermagem frente ao paciente no processo da terminalidade; Implicações do preparo ou despreparo do profissional de enfermagem na assistência ao paciente no processo de morte. Após a revisão, observamos que alguns profissionais de enfermagem não estão preparados emocionalmente para lidar com o paciente morrente, tal despreparo reflete na assistência prestada, de forma que este profissional na maioria das vezes assume uma postura de afastamento do paciente e família. Palavras-chave: Terminalidade; Morte; Assistência de enfermagem.

\section{THE COPING EMOTIONAL PROFESSIONAL NURSING IN PATIENT CARE IN THE PROCESS OF LIFE TERMINALITY}

\begin{abstract}
Abstrat
This is a bibliographic, descriptive review of qualitative nature, whose objectives were to: Understand the feelings of nursing professionals across the ill patient in the process of end of life; Discuss the reasons why they adopt certain postures (removal or approximation) on the situation and discuss the implications of this lack of preparation or staging professional in patient care in the process of dying. The database Lilacs
\end{abstract}


and Bireme was used, considering the publications from 2002-2012.After analysis of the items three categories emerged: Feelings of nursing professionals across the ill patient in the process of Terminality; Attitudes of nurses towards the patient in a terminal process; Implications of preparation or lack of preparation in professional nursing care to patients in the dying process. Upon review, we observed that some nurses are not prepared emotionally to deal with the patient morrente such unpreparedness reflects the care provided, so that this professional most often assumes a posture of taking the patient and family.

Keywords: Terminally; Death; Nursing assistance.

\section{INTRODUÇÃO}

Durante a vivência de estágio na UTI Cirúrgica em um determinado hospital da rede pública da cidade do Salvador na disciplina Estágio Supervisionado I do curso de enfermagem da UNIFACS, quando em conversa com uma enfermeira, a mesma relatou sobre seus sentimentos frente a um paciente sem possibilidades terapêuticas medicamentosas. Expressou que não se sente capaz para prestar uma assistência humanizada ao paciente nesta condição, sendo a sua conduta especificamente mecânica sem nenhum tipo de aproximação emocional e afetiva tanto com o paciente quanto com seus familiares.

Diante desse relato desencadeou o interesse em estudar a vulnerabilidade emocional dos profissionais de enfermagem em vivenciar tal situação, isto porque como forma de não se envolver com o sofrimento do paciente, essa profissional de enfermagem teve por conduta o afastamento do paciente e seus familiares, o que pode resultar em negligência nos cuidados, tornando a assistência mecanizada e direcionada somente para manter a vida sem se preocupar com a qualidade, e não para oferecer uma boa morte ao paciente. ${ }^{(1)}$

Acredita-se que tais atitudes estão intimamente relacionadas ao despreparo emocional, o medo de expor suas emoções e sentimentos ou suportar a situação de estresse frente à morte.

No entanto questiona-se, se o profissional de enfermagem está preparado para enfrentar tais si- tuações, pois, no seu processo de formação este é capacitado a prestar assistência ao paciente com vistas à sua melhora e retorno ao convívio social e familiar, não para acompanhar a sua morte, o que pode resultar em um sentimento de culpa, impotência e frustração, sendo percebido como doloroso, e uma sensação de dever não cumprido, ou seja, uma falha na assistência prestada. ${ }^{(2)}$

O paciente gravemente enfermo muitas vezes é tratado como um objeto pela equipe de saúde, ou seja, alguém que não tem mais o direto de opinar em sua vida, normalmente sempre há alguém para decidir e tomar as decisões, mas, vale lembrar que o paciente terminal também tem sentimentos, opiniões, desejos e necessidade de ser ouvido.(3)

Segundo Brunner(4)

$$
\begin{aligned}
& E ́ \text { de fundamental importância que a equipe } \\
& \text { multidiciplinar esteja preparada para, apoiar e } \\
& \text { orientar sobre as decisões a serem adotadas durante } \\
& \text { o tratamento. O profissional de enfermagem tem o } \\
& \text { papel de avaliar a resposta do paciente e da familia ao } \\
& \text { diagnóstico e ao tratamento planejado, avaliando as } \\
& \text { reações dos mesmos e fornecendo assistência e apoio } \\
& \text { quando o cliente e a familia confrontam e aprendem a } \\
& \text { lidar com os novos problemas. }
\end{aligned}
$$

No desenvolvimento de suas atividades, os profissionais de enfermagem devem estar preparados para cuidar de pessoas com comprometimentos emocionais, psicológicos e sociais, assim como auxiliar na adaptação de limitações decorrentes da 
evolução e/ou tratamento da doença, preconizando uma assistência de qualidade ao indivíduo.(5)

Diante do exposto, questiona-se se o profissional de enfermagem está ou não apto para enfrentar e lidar emocionalmente com o processo de terminalidade da vida do paciente, e quais as implicações deste comportamento no cuidado prestado ao paciente e família. Para tanto se traçou como objetivos:

- Compreender os sentimentos dos profissionais de enfermagem frente ao paciente enfermo no processo da terminalidade da vida;

- Discutir os motivos que levam os profissionais de enfermagem a adotar determinadas posturas (de afastamento ou aproximação) diante desta situação;

- Discutir as implicações do preparo ou despreparo do profissional de enfermagem na assistência ao paciente no processo de morte.

Sendo assim, este estudo torna-se, relevante, pois trata de discutir a pertinência do assunto morte e terminalidade da vida como conteúdo, por agregar conhecimento e valores de forma que facilite a compreensão destes profissionais sobre a real importância da sua assistência, de forma a fortalecer e facilitar o enfrentamento do outro que está próximo ao fim da vida, preconizando sempre o cuidado humanizado. Além disso, este justifica-se por identificar a atuação e dificuldades encontradas durante a assistência aos pacientes gravemente enfermos

\section{MATERIAL E MÉTODOS}

Revisão bibliográfica com abordagem de caráter descritivo e qualitativo. O levantamento bibliográfico foi realizado na base de dados do Scielo, Bireme à partir do DeCS e Lilacs, foram consideradas as publicações dos anos 2002-2012, em língua portuguesa, utilizando os descritores terminalidade, morte e assistência de enfermagem. A pesquisa foi realizada entre os meses: julho de 2013 à março de 2014 .

Foram selecionados apenas artigos originais e que tinham relação com o objetivo proposto Compreender os sentimentos dos profissionais de enfermagem frente ao paciente enfermo no processo da terminalidade da vida.

Como critério de inclusão foram considerados os artigos com temas acerca da abordagem emocional dos profissionais de enfermagem na assistência ao paciente terminal. Como critério de exclusão foram descartados aqueles que não tiveram pertinência com o objeto do estudo, os que foram publicados há mais de 10 anos e que em seu resumo apresentassem uma abordagem diferente da proposta principal do artigo. Para o estudo foram selecionados 30 artigos, após aplicação do critério de exclusão foram eleitos 15 , dos quais submeteram-se a leitura minuciosa, e analisados à luz dos objetivos do estudo. 
Quadro 1 - Quadro de Revisão

(continua)

\begin{tabular}{|c|c|c|c|c|c|}
\hline AUTOR (ES) & REVISTA & TEMA & $\begin{array}{l}\text { População/ } \\
\text { METOdologia }\end{array}$ & OBJEtivo & RESULtAdos / DiscussÃo \\
\hline $\begin{array}{l}\text { Wilker Invenção } \\
\text { Rita da Cruz }\end{array}$ & $\begin{array}{l}\text { Revista Gaúcha } \\
\text { de Enfermagem }\end{array}$ & $\begin{array}{l}\text { A morte e o } \\
\text { morrer no } \\
\text { processo de } \\
\text { formação do } \\
\text { enfermeiro. }\end{array}$ & $\begin{array}{l}\text { Trata-se de um } \\
\text { estudo qualitativo. Os } \\
\text { sujeitos foram sete } \\
\text { alunos regularmente } \\
\text { matriculados na disciplina } \\
\text { Estágio Supervisionado } \\
\text { II, último do curso. Para } \\
\text { coleta de dados utilizou- } \\
\text { se entrevista com roteiro } \\
\text { semi-estruturado e para } \\
\text { análise, o método de } \\
\text { análise de conteúdo. }\end{array}$ & $\begin{array}{l}\text { Esta pesquisa teve } \\
\text { como objetivo conhecer } \\
\text { o preparo para o } \\
\text { enfrentamento da morte } \\
\text { e o morrer no processo } \\
\text { de formação do } \\
\text { estudante de graduação } \\
\text { em enfermagem da } \\
\text { Universidade Estadual } \\
\text { de Feira de Santana } \\
\text { (UEFS), Bahia. }\end{array}$ & $\begin{array}{l}\text { Depreende-se que o processo } \\
\text { de morte e morrer não vem } \\
\text { sendo trabalhado de maneira } \\
\text { que atenda às necessidades } \\
\text { dos alunos que no seu fazer } \\
\text { diário vivenciam situações que } \\
\text { exigem instrumentalização na } \\
\text { assistência à pessoa para que } \\
\text { tenha uma morte digna. }\end{array}$ \\
\hline $\begin{array}{l}\text { Helena Eri Shimizu } \\
\text { Ano } 2007\end{array}$ & $\begin{array}{l}\text { Revista Brasileira } \\
\text { de Enfermagem }\end{array}$ & $\begin{array}{l}\text { Como os } \\
\text { trabalhadores } \\
\text { de enfermagem } \\
\text { enfrentam o } \\
\text { processo de } \\
\text { morrer. }\end{array}$ & $\begin{array}{l}\text { Trata-se de um estudo } \\
\text { qualitativo que } \\
\text { utiliza a Teoria das } \\
\text { representações sociais. } \\
\text { Realizaram-se entrevistas } \\
\text { semi-estruturadas com } \\
\text { quatro técnicos e doze } \\
\text { auxiliares de enfermagem } \\
\text { que trabalham em UTls. }\end{array}$ & $\begin{array}{l}\text { Este estudo teve } \\
\text { como objetivos } \\
\text { identificar e analisar } \\
\text { as representações e } \\
\text { sentimentos vivenciados, } \\
\text { os mecanismos de } \\
\text { defesa e as estratégias } \\
\text { desenvolvidas pelos } \\
\text { trabalhadores } \\
\text { de enfermagem } \\
\text { no processo de } \\
\text { enfrentamento da morte } \\
\text { dos pacientes. }\end{array}$ & $\begin{array}{l}\text { Os resultados evidenciam } \\
\text { que os trabalhadores } \\
\text { de enfermagem sofrem } \\
\text { intensamente ao cuidar dos } \\
\text { pacientes em processo de } \\
\text { morrer. }\end{array}$ \\
\hline $\begin{array}{l}\text { Rudval Souza } \\
\text { Ana Emília Álvaro } \\
\text { Pereira }\end{array}$ & $\begin{array}{l}\text { Revista da } \\
\text { Escola de } \\
\text { Enfermagem da } \\
\text { USP }\end{array}$ & $\begin{array}{l}\text { Cuidando do } \\
\text { paciente no } \\
\text { processo de } \\
\text { Morte na Unidade } \\
\text { de Terapia } \\
\text { Intensiva }\end{array}$ & $\begin{array}{l}\text { Foram entrevistadas dez } \\
\text { enfermeiras. A pesquisa } \\
\text { de campo foi realizada } \\
\text { em uma Unidade de } \\
\text { Terapia Intensiva de um } \\
\text { hospital público de ensino. }\end{array}$ & $\begin{array}{l}\text { Este estudo buscou } \\
\text { caracterizar o } \\
\text { desenvolvimento do } \\
\text { cuidar/cuidado de } \\
\text { enfermagem numa UTI } \\
\text { ao paciente fora de } \\
\text { possibilidade de cura } \\
\text { (PFPC) por enfermeiros. }\end{array}$ & $\begin{array}{l}\text { Os Resultados evidenciam } \\
\text { que as (os) enfermeiras (os) } \\
\text { necessitam compreender a } \\
\text { morte como parte do ciclo } \\
\text { vital e repensar o cuidar/ } \\
\text { cuidado como essência da } \\
\text { enfermagem, ampliando as } \\
\text { discussões sobre a temática } \\
\text { tanto no âmbito acadêmico } \\
\text { quanto na prática diária. }\end{array}$ \\
\hline
\end{tabular}


Quadro 1 - Quadro de Revisão

(continuação)

\begin{tabular}{|c|c|c|c|c|c|}
\hline AUTOR (ES) & REVISTA & TEMA & $\begin{array}{l}\text { PopulaçÃo/ } \\
\text { METOdOLOGIA }\end{array}$ & OBJetivo & RESULTADOs / DiscussÃo \\
\hline $\begin{array}{l}\text { Mertieli Ulzbacher } \\
\text { Anelise Reck } \\
\text { Eniva Stumm } \\
\text { Leila Hildebrandt } \\
\text { Ano } 2009\end{array}$ & $\begin{array}{l}\text { Revistas } \\
\text { Eletrônicas } \\
\text { PUCRS }\end{array}$ & $\begin{array}{l}\text { O enfermeiro } \\
\text { em Unidade } \\
\text { de Tratamento } \\
\text { Intensivo } \\
\text { vivenciando e } \\
\text { enfrentando } \\
\text { situações de } \\
\text { morte e morrer }\end{array}$ & $\begin{array}{l}\text { Foi realizada uma } \\
\text { pesquisa qualitativa } \\
\text { e descritiva em três } \\
\text { hospitais gerais de um } \\
\text { município da região } \\
\text { noroeste do Rio Grande } \\
\text { do Sul. Os sujeitos } \\
\text { foram dez enfermeiros } \\
\text { que atuam em Unidade } \\
\text { de Terapia Intensiva. } \\
\text { Para a coleta de dados } \\
\text { utilizou-se entrevista } \\
\text { semi-estruturadas. A } \\
\text { análise das informações } \\
\text { baseou-se nos passos } \\
\text { metodológicos } \\
\text { preconizados para análise } \\
\text { temática. }\end{array}$ & $\begin{array}{l}\text { Avaliar percepções de } \\
\text { enfermeiros que atuam } \\
\text { em Unidades de Terapia } \\
\text { Intensiva acerca da } \\
\text { morte de pacientes } \\
\text { e as estratégias de } \\
\text { enfrentamento por eles } \\
\text { utilizadas. }\end{array}$ & $\begin{array}{l}\text { As informações permitiram } \\
\text { elaborar uma categoria } \\
\text { de análise que versa sobre } \\
\text { percepções, sentimentos } \\
\text { e mecanismos de } \\
\text { enfrentamento frente à morte } \\
\text { e ao morrer vivenciados pelos } \\
\text { enfermeiros. } \\
\text { O estudo possibilita reflexão, } \\
\text { discussão e socialização dos } \\
\text { sentimentos vivenciados } \\
\text { no processo de morte de } \\
\text { um paciente internado } \\
\text { em Unidade de Terapia } \\
\text { Intensiva, podendo facilitar } \\
\text { as intervenções junto a este, } \\
\text { minimizar o sofrimento dos } \\
\text { profissionais e qualificar a } \\
\text { assistência. }\end{array}$ \\
\hline $\begin{array}{l}\text { Ananda Rosa } \\
\text { Valéria Lunardi } \\
\text { Edison Barlem } \\
\text { Wilson Filho } \\
\text { Ano } 2006\end{array}$ & $\begin{array}{l}\text { Revista Ciência, } \\
\text { Cuidado e } \\
\text { Saúde. }\end{array}$ & $\begin{array}{l}\text { Percepções das } \\
\text { enfermeiras } \\
\text { frente aos } \\
\text { sentimentos de } \\
\text { quem } \\
\text { Vivencia o } \\
\text { processo de } \\
\text { morrer e morte }\end{array}$ & $\begin{array}{l}\text { Realizamos uma } \\
\text { pesquisa qualitativa, } \\
\text { mediante entrevistas } \\
\text { semi-estruturadas com } \\
\text { enfermeiras atuantes em } \\
\text { unidades de tratamento } \\
\text { intensivo de dois hospitais } \\
\text { do Extremo-Sul do país. } \\
\text { Através da análise } \\
\text { textual, construímos duas } \\
\text { categorias: pacientes e } \\
\text { familiares sob o olhar } \\
\text { das enfermeiras; e } \\
\text { dificuldades e estratégias } \\
\text { das enfermeiras diante } \\
\text { do processo de morrer e } \\
\text { morte. }\end{array}$ & $\begin{array}{l}\text { Tivemos como objetivo } \\
\text { conhecer a percepção } \\
\text { das enfermeiras acerca } \\
\text { das manifestações e } \\
\text { sentimentos expressos } \\
\text { por pacientes e } \\
\text { familiares que vivenciam } \\
\text { este processo. }\end{array}$ & $\begin{array}{l}\text { As enfermeiras percebem } \\
\text { nos pacientes sentimentos } \\
\text { de solidão, de medo, da } \\
\text { morte como um alívio, de dor, } \\
\text { raiva e revolta, entre outros; } \\
\text { e nos familiares, angústia, } \\
\text { impotência e medo. }\end{array}$ \\
\hline
\end{tabular}


Quadro 1 - Quadro de Revisão

(continuação)

\begin{tabular}{|c|c|c|c|c|c|}
\hline AUTOR (ES) & REVISTA & TEMA & $\begin{array}{l}\text { PopulaçÃo/ } \\
\text { METOdOLOGIA }\end{array}$ & ObJetivo & RESULtAdos / Discussão \\
\hline $\begin{array}{l}\text { Beatriz Gutierrez } \\
\text { Maria Helena } \\
\text { Ciampone } \\
\text { Ano } 2006\end{array}$ & $\begin{array}{l}\text { Acta Paulista de } \\
\text { Enfermagem }\end{array}$ & $\begin{array}{l}\text { Profissionais de } \\
\text { enfermagem } \\
\text { frente ao } \\
\text { processo de } \\
\text { morte em } \\
\text { Unidades de } \\
\text { Terapia Intensiva. }\end{array}$ & $\begin{array}{l}\text { A pesquisa foi qualitativa } \\
\text { e os dados foram } \\
\text { analisados segundo } \\
\text { a análise temática, } \\
\text { estruturada com base } \\
\text { na psicodinâmica do } \\
\text { trabalho. }\end{array}$ & $\begin{array}{l}\text { Identificar e analisar } \\
\text { os sentimentos e } \\
\text { as percepções dos } \\
\text { profissionais de } \\
\text { enfermagem de } \\
\text { unidades de terapia } \\
\text { intensiva, no } \\
\text { enfrentamento do } \\
\text { processo de morrer e } \\
\text { propor intervenções } \\
\text { que potencializem } \\
\text { esse enfrentamento na } \\
\text { assistência prestada ao } \\
\text { paciente/ familiares. }\end{array}$ & $\begin{array}{l}\text { Os resultados mostraram a } \\
\text { necessidade de se implantar } \\
\text { encontros sistematizados, } \\
\text { nos quais esses profissionais } \\
\text { tenham a oportunidade } \\
\text { de expor suas satisfações, } \\
\text { angústias e medos durante } \\
\text { esse processo. }\end{array}$ \\
\hline $\begin{array}{l}\text { Marina Mota } \\
\text { Giovana Gomes } \\
\text { Monique Coelho } \\
\text { Wilson Danilo } \\
\text { Lenice Sousa } \\
\text { Ano } 2011\end{array}$ & $\begin{array}{l}\text { Revista Gaúcha } \\
\text { de Enfermagem }\end{array}$ & $\begin{array}{l}\text { Reações e } \\
\text { Sentimentos de } \\
\text { Profissionais da } \\
\text { Enfermagem } \\
\text { Frente à morte } \\
\text { dos Pacientes sob } \\
\text { seus cuidados. }\end{array}$ & $\begin{array}{l}\text { Trata-se de uma pesquisa } \\
\text { qualitativa desenvolvida } \\
\text { na Unidade de Clínica } \\
\text { Médica de um Hospital } \\
\text { Universitário do sul do } \\
\text { Brasil. A população de } \\
\text { estudo foi composta } \\
\text { por quatro enfermeiras } \\
\text { e cinco técnicos de } \\
\text { enfermagem atuantes no } \\
\text { setor. A coleta de dados } \\
\text { foi realizada no segundo } \\
\text { semestre de } 2006 \\
\text { através de entrevistas } \\
\text { semiestruturadas. Os } \\
\text { dados foram analisados } \\
\text { pela técnica de Análise } \\
\text { Temática. }\end{array}$ & $\begin{array}{l}\text { Objetivou-se } \\
\text { conhecer as reações } \\
\text { e sentimentos de } \\
\text { profissionais da } \\
\text { enfermagem frente à } \\
\text { morte do paciente sob } \\
\text { seus cuidados. }\end{array}$ & $\begin{array}{l}\text { A análise dos dados gerou } \\
\text { três categorias: reações dos } \\
\text { profissionais da enfermagem } \\
\text { frente à morte no cotidiano } \\
\text { do trabalho, sentimentos } \\
\text { frente à morte no cotidiano } \\
\text { do trabalho e a enfermagem } \\
\text { frente ao preparo do corpo } \\
\text { após a morte. Concluiu-se que } \\
\text { é necessário criar um espaço } \\
\text { no ambiente de trabalho para } \\
\text { se discutir acerca da morte } \\
\text { a fim de instrumentalizar os } \\
\text { trabalhadores para o seu } \\
\text { enfrentamento. }\end{array}$ \\
\hline
\end{tabular}


Quadro 1 - Quadro de Revisão

(continuação)

\begin{tabular}{|c|c|c|c|c|c|}
\hline AUTOR (ES) & ReVISTA & TEMA & $\begin{array}{l}\text { POPULAÇÃO/ } \\
\text { METODOLOGIA }\end{array}$ & ObJetivo & RESULtAdos / Discussão \\
\hline $\begin{array}{l}\text { Daniella Faria } \\
\text { Eulália Maia }\end{array}$ & $\begin{array}{l}\text { Revista Latino- } \\
\text { Americana de } \\
\text { Enfermagem }\end{array}$ & $\begin{array}{l}\text { Ansiedades e } \\
\text { sentimentos de } \\
\text { Profissionais da } \\
\text { Enfermagem } \\
\text { nas Situações de } \\
\text { Terminalidade em } \\
\text { oncologia. }\end{array}$ & $\begin{array}{l}\text { Investigação de caráter } \\
\text { transversal que avaliou } \\
\text { o nível de ansiedade da } \\
\text { equipe de enfermagem } \\
\text { que lida com o paciente } \\
\text { terminal com câncer. } \\
\text { Foram analisados } 50 \\
\text { auxiliares e técnicos } \\
\text { de enfermagem do } \\
\text { hospital de referência de } \\
\text { atendimento ao câncer do } \\
\text { Rio Grande do Norte. Os } \\
\text { dados foram coletados } \\
\text { através de questionário } \\
\text { e do Inventário de } \\
\text { Ansiedade Traço-Estado. }\end{array}$ & $\begin{array}{l}\text { Avaliou o nível de } \\
\text { ansiedade da equipe de } \\
\text { enfermagem que lida } \\
\text { com o paciente terminal } \\
\text { com câncer, procurando } \\
\text { identificar os fatores } \\
\text { que a influenciam, bem } \\
\text { como os sentimentos } \\
\text { dos profissionais frente } \\
\text { ao atendimento destes } \\
\text { pacientes. }\end{array}$ & $\begin{array}{l}\text { Os resultados revelaram } \\
\text { que } 69,8 \% \text { dos profissionais } \\
\text { possuem Ansiedade-Estado } \\
\text { média e } 30,2 \% \text { alta. } ~ \\
\text { número de pacientes } \\
\text { atendidos e 'trabalhar em } \\
\text { outra instituição' interferiram } \\
\text { na Ansiedade-Estado. Os } \\
\text { sentimentos mais destacados } \\
\text { foram sofrimento e tristeza, e } \\
\text { 'criança' foi apontada como } \\
\text { sendo a faixa-etária mais } \\
\text { difícil de lidar. Verifica-se a } \\
\text { necessidade de realização } \\
\text { de estratégias de apoio para } \\
\text { profissionais a fim de reduzir } \\
\text { e/ou prevenir altos níveis de } \\
\text { ansiedade e estresse. }\end{array}$ \\
\hline $\begin{array}{l}\text { Ylana Karine } \\
\text { Diego Bonfada } \\
\text { Ano } 2012\end{array}$ & $\begin{array}{l}\text { Revista da Rede } \\
\text { de Enfermagem } \\
\text { do Nordeste }\end{array}$ & $\begin{array}{l}\text { Refletindo } \\
\text { sobre finitude: } \\
\text { um enfoque na } \\
\text { assistência de } \\
\text { enfermagem } \\
\text { frente à } \\
\text { Terminalidade. }\end{array}$ & $\begin{array}{l}\text { A coleta de dados se } \\
\text { deu no período de junho } \\
\text { a agosto de } 2010 \text { por } \\
\text { meio de observação } \\
\text { livre e entrevistas semi- } \\
\text { estruturadas, tendo } \\
\text { sido entrevistados } \\
\text { ll profissionais de } \\
\text { enfermagem. Para análise } \\
\text { dos dados escolheu-se } \\
\text { o método de Análise } \\
\text { Temática. } \\
\text { Unidade de Terapia } \\
\text { Intensiva geral de um } \\
\text { hospital referência em } \\
\text { oncologia no Estado do } \\
\text { Rio Grande do Norte, } \\
\text { Brasil. }\end{array}$ & $\begin{array}{l}\text { Neste estudo, } \\
\text { objetivou-se analisar } \\
\text { as implicações das } \\
\text { concepções dos } \\
\text { profissionais de } \\
\text { enfermagem sobre a } \\
\text { morte e o morrer na } \\
\text { assistência prestada } \\
\text { ao paciente terminal } \\
\text { da Unidade de Terapia } \\
\text { Intensiva geral de um } \\
\text { hospital referência em } \\
\text { oncologia no Estado do } \\
\text { Rio Grande do Norte, } \\
\text { Brasil. }\end{array}$ & $\begin{array}{l}\text { Os resultados obtidos } \\
\text { apontaram para uma } \\
\text { multiplicidade de sentimentos } \\
\text { e dimensões conceituais } \\
\text { relativas ao processo de } \\
\text { morte como determinantes } \\
\text { das ações de cuidado aos } \\
\text { pacientes terminais. }\end{array}$ \\
\hline
\end{tabular}


Quadro 1 - Quadro de Revisão

(continuação)

\begin{tabular}{|c|c|c|c|c|c|}
\hline AUTOR (ES) & Revista & TEMA & $\begin{array}{l}\text { PopulaçÃo/ } \\
\text { METOdOLOGIA }\end{array}$ & ObJetivo & RESULTADos / DiscussÃo \\
\hline $\begin{array}{l}\text { Antônio Silva } \\
\text { Erasmo Ruiz }\end{array}$ & $\begin{array}{l}\text { Estudos de } \\
\text { Psicologia } \\
\text { (Campinas) }\end{array}$ & $\begin{array}{l}\text { Cuidar, morte } \\
\text { e morrer: } \\
\text { Significação para } \\
\text { profissionais de } \\
\text { enfermagem. }\end{array}$ & $\begin{array}{l}\text { Utilizamo-nos da } \\
\text { Etnometodologia, a } \\
\text { qual nos possibilitou } \\
\text { observar, interagir com } \\
\text { o grupo e entrevistá-lo } \\
\text { a fim de compreender } \\
\text { o fenômeno. O grupo } \\
\text { investigado constituiu-se } \\
\text { de } 10 \text { profissionais de } \\
\text { enfermagem lotados na } \\
\text { sala de ressuscitação } \\
\text { de um hospital de } \\
\text { referência de Fortaleza, } \\
\text { especializado em } \\
\text { atendimento a pacientes } \\
\text { politraumatizados. }\end{array}$ & $\begin{array}{l}\text { O presente trabalho } \\
\text { objetivou compreender } \\
\text { as significações dos } \\
\text { profissionais de saúde } \\
\text { que lidam com pacientes } \\
\text { graves acerca da morte. }\end{array}$ & $\begin{array}{l}\text { O despreparo tanatológico } \\
\text { produz uma série de reações } \\
\text { nos profissionais, os quais } \\
\text { tendem a significar a morte } \\
\text { e o morrer, a partir das } \\
\text { condições de trabalho, das } \\
\text { relações de poder, envolvendo } \\
\text { aspectos políticos, éticos, } \\
\text { culturais e socioeconômicos. } \\
\text { Percebe-se necessária a } \\
\text { expansão do conteúdo } \\
\text { tanático em âmbito } \\
\text { acadêmico e profissional } \\
\text { como meio de otimizar a } \\
\text { assistência e permitir o } \\
\text { autoconhecimento. }\end{array}$ \\
\hline $\begin{array}{l}\text { Juliana Costa } \\
\text { Regina Lima } \\
\text { Ano } 2005\end{array}$ & $\begin{array}{l}\text { Revista Latino- } \\
\text { Americana de } \\
\text { Enfermagem }\end{array}$ & $\begin{array}{l}\text { Luto da equipe: } \\
\text { Revelações dos } \\
\text { profissionais de } \\
\text { enfermagem } \\
\text { sobre cuidado } \\
\text { á criança/ } \\
\text { Adolescente } \\
\text { no processo de } \\
\text { morte e morrer. }\end{array}$ & $\begin{array}{l}\text { Através de pesquisa } \\
\text { descritiva-exploratória } \\
\text { com abordagem } \\
\text { qualitativa. A coleta } \\
\text { de dados foi realizada } \\
\text { mediante entrevistas } \\
\text { com profissionais } \\
\text { de enfermagem que } \\
\text { trabalham em clínicas } \\
\text { com leitos pediátricos em } \\
\text { um hospital-escola }\end{array}$ & $\begin{array}{l}\text { O objetivo do presente } \\
\text { estudo é investigar } \\
\text { como os profissionais de } \\
\text { enfermagem vivenciam } \\
\text { o luto frente à morte de } \\
\text { crianças/ adolescentes } \\
\text { hospitalizados }\end{array}$ & $\begin{array}{l}\text { Os dados empíricos } \\
\text { evidenciaram que esses } \\
\text { profissionais necessitam } \\
\text { de suporte emocional para } \\
\text { viverem o luto e prevenirem } \\
\text { a Síndrome de Burnout. } \\
\text { Recomenda-se que seja } \\
\text { incluído nos currículos o tema } \\
\text { da morte e que as instituições } \\
\text { hospitalares busquem a } \\
\text { educação permanente como } \\
\text { estratégia para promover } \\
\text { mudanças de atitudes } \\
\text { e comportamentos dos } \\
\text { profissionais junto ao paciente } \\
\text { que está morrendo. }\end{array}$ \\
\hline $\begin{array}{l}\text { Beatriz Gutierrez } \\
\text { Maria Helena } \\
\text { Ciampone } \\
\text { Ano } 2007\end{array}$ & $\begin{array}{l}\text { Revista da } \\
\text { Escola de } \\
\text { Enfermagem da } \\
\text { USP }\end{array}$ & $\begin{array}{l}\text { O processo de } \\
\text { morrer e a morte } \\
\text { no enfoque dos } \\
\text { profissionais de } \\
\text { enfermagem de } \\
\text { UTIS. }\end{array}$ & $\begin{array}{l}\text { Os dados foram coletados } \\
\text { por meio de entrevistas } \\
\text { individuais e grupo focal } \\
\text { e analisados segundo } \\
\text { técnicas qualitativas. }\end{array}$ & $\begin{array}{l}\text { O objetivo deste } \\
\text { estudo foi identificar as } \\
\text { concepções culturais } \\
\text { relacionadas ao processo } \\
\text { de morrer e à morte no } \\
\text { contexto de trabalho } \\
\text { dos profissionais de } \\
\text { enfermagem de UTIs. } \\
\text { Foram sujeitos deste } \\
\text { estudo as enfermeiras, } \\
\text { técnicos e auxiliares } \\
\text { de enfermagem que } \\
\text { trabalham nessas UTIs. }\end{array}$ & $\begin{array}{l}\text { As narrativas mostram } \\
\text { múltiplas dimensões } \\
\text { determinantes das atitudes } \\
\text { e ações profissionais, que } \\
\text { vão além do conhecimento } \\
\text { técnico. Fica evidente que } \\
\text { esses profissionais procuram } \\
\text { refúgio nas suas crenças e } \\
\text { valores para suportar um } \\
\text { trabalho que lhes impõe } \\
\text { tantas cargas. }\end{array}$ \\
\hline
\end{tabular}


Quadro 1 - Quadro de Revisão

(conclusão)

\begin{tabular}{|c|c|c|c|c|c|}
\hline AUTOR (ES) & REVISTA & TEMA & $\begin{array}{l}\text { População/ } \\
\text { METOdOLOGIA }\end{array}$ & OBJetivo & RESULTADOs / DiscussÃo \\
\hline $\begin{array}{l}\text { Priscila Fernandes } \\
\text { Alexandra Iglesias } \\
\text { Luziane Avellar }\end{array}$ & $\begin{array}{l}\text { Psicologia: } \\
\text { Teoria e Prática }\end{array}$ & $\begin{array}{l}\text { O técnico de } \\
\text { enfermagem } \\
\text { diante da morte: } \\
\text { concepções } \\
\text { de morte para } \\
\text { técnicos de } \\
\text { enfermagem em } \\
\text { oncologia e sua } \\
\text { implicações na } \\
\text { rotina de trabalho } \\
\text { e vida cotidiana. }\end{array}$ & $\begin{array}{l}\text { Para atingir os objetivos } \\
\text { propostos, realizaram-se } \\
\text { observações Participantes } \\
\text { registradas em um diário } \\
\text { de campo e entrevistas } \\
\text { semiestruturadas que } \\
\text { foram gravadas e } \\
\text { transcritas na íntegra. Os } \\
\text { dados foram submetidos } \\
\text { à análise qualitativa que } \\
\text { foi entendida como um } \\
\text { processo de produção de } \\
\text { sentido. }\end{array}$ & $\begin{array}{l}\text { O objetivo deste } \\
\text { trabalho foi conhecer } \\
\text { as concepções de } \\
\text { morte para técnicos de } \\
\text { enfermagem que lidam } \\
\text { com pacientes terminais } \\
\text { em um hospital público } \\
\text { da Grande Vitória. } \\
\text { Pretendeu-se apreender } \\
\text { como esses profissionais } \\
\text { lidavam com a morte e } \\
\text { como isso interferia em } \\
\text { suas vidas cotidianas } \\
\text { e em suas rotinas de } \\
\text { trabalho. }\end{array}$ & $\begin{array}{l}\text { Os dados indicaram que } \\
\text { a concepção de morte } \\
\text { mais encontrada no grupo } \\
\text { pesquisado foi a de que a } \\
\text { morte é um acontecimento } \\
\text { normal que faz parte da } \\
\text { rotina de trabalho, mas é um } \\
\text { tema que deve ser evitado. }\end{array}$ \\
\hline $\begin{array}{l}\text { Moema Borges } \\
\text { Nayara Mendes } \\
\text { Ano } 2012\end{array}$ & $\begin{array}{l}\text { Revista Brasileira } \\
\text { de Enfermagem }\end{array}$ & $\begin{array}{l}\text { Representações } \\
\text { de profissionais } \\
\text { de saúde sobre } \\
\text { a morte e o } \\
\text { processo de } \\
\text { morrer. }\end{array}$ & $\begin{array}{l}\text { Trata-se de uma pesquisa } \\
\text { qualitativa de natureza } \\
\text { exploratória. Foram } \\
\text { entrevistados cinco } \\
\text { profissionais de saúde } \\
\text { que prestam assistência } \\
\text { a pacientes fora de } \\
\text { possibilidades de cura. }\end{array}$ & $\begin{array}{l}\text { A pesquisa objetivou } \\
\text { apreender as } \\
\text { representações sociais } \\
\text { da morte e do processo } \\
\text { de morrer para os } \\
\text { profissionais } \\
\text { de saúde. }\end{array}$ & $\begin{array}{l}\text { Os resultados ressaltam a } \\
\text { necessidade de investir na } \\
\text { capacitação dos alunos não } \\
\text { somente no desenvolvimento } \\
\text { de habilidades técnicas, mas } \\
\text { também no desenvolvimento } \\
\text { de habilidades interpessoais, } \\
\text { elementos fundamentais para } \\
\text { o cuidado humano, sobretudo } \\
\text { diante a morte. }\end{array}$ \\
\hline $\begin{array}{l}\text { Patrícia Sanches } \\
\text { Maria Carvalho } \\
\text { Ano } 2009\end{array}$ & $\begin{array}{l}\text { Revista Gaúcha } \\
\text { de Enfermagem }\end{array}$ & $\begin{array}{l}\text { Vivência dos } \\
\text { enfermeiros } \\
\text { de unidade de } \\
\text { terapia intensiva } \\
\text { frente à morte e o } \\
\text { morrer. }\end{array}$ & $\begin{array}{l}\text { Os sujeitos foram os } \\
\text { enfermeiros que atuam } \\
\text { em uma Unidade de } \\
\text { Terapia Intensiva de } \\
\text { adultos. Foi utilizada } \\
\text { a metodologia } \\
\text { fenomenológica e os } \\
\text { dados foram colhidos por } \\
\text { meio de uma entrevista } \\
\text { semiestruturada. }\end{array}$ & $\begin{array}{l}\text { O estudo teve como } \\
\text { objetivo compreender } \\
\text { como os enfermeiros } \\
\text { vivenciam o processo } \\
\text { de morte e o morrer dos } \\
\text { pacientes. }\end{array}$ & $\begin{array}{l}\text { Na análise, procedeu-se } \\
\text { segundo a descrição, } \\
\text { redução e compreensão } \\
\text { fenomenológica, e, a partir } \\
\text { dela, foram desveladas } \\
\text { as seguintes categorias: a } \\
\text { obstinação terapêutica como } \\
\text { um percalço no processo } \\
\text { de morte e morrer; a difícil } \\
\text { convivência com a equipe } \\
\text { multiprofissional e o processo } \\
\text { de morte e morrer; a dinâmica } \\
\text { do trabalho e suas implicações } \\
\text { na morte e morrer dos } \\
\text { pacientes. Os profissionais } \\
\text { precisam compreender que a } \\
\text { morte e o morrer fazem parte } \\
\text { inalienável da vida e não um } \\
\text { desafio a ser sempre vencido. }\end{array}$ \\
\hline
\end{tabular}


Foi realizado um roteiro através de um quadro para otimizar a análise dos artigos: autor, ano de publicação, tema, objeto, objetivo, resultado/análise. A partir de então, surgiram 03 categorias: Sentimentos dos profissionais de enfermagem frente ao paciente enfermo no processo da terminalidade; Postura dos profissionais de enfermagem frente ao paciente no processo da terminalidade; Implicações do preparo ou despreparo do profissional de enfermagem na assistência ao paciente no processo de morte. A pesquisa foi realizada respeitando os direitos autorais das fontes pesquisadas.

\section{RESULTADOS}

\section{CATEGORIA I - SENTIMENTOS DOS PROFISSIONAIS DE ENFERMAGEM FRENTE AO PACIENTE ENFERMO NO PROCESSO DA TERMINALIDADE}

Para os profissionais de enfermagem que trabaIham com pacientes sem possibilidades terapêuticas é uma tarefa muito difícil e que desencadeiam sentimentos de culpa, tristeza, ansiedade, raiva e impotência. ${ }^{(6,7,1,8,9,10,11)}$

O contato com o paciente no processo de terminalidade leva o profissional de enfermagem a um desgaste emocional, em que os sentimentos se expressam de forma confusa. ${ }^{(7)}$

Estes profissionais têm uma grande dificuldade em lidar e aceitar a morte, pelo fato de que não se sabe realmente o seu significado. O desconhecido causa medo e angústia dificultando a vivência neste processo. ${ }^{(12)}$ Pesquisas expõem que os profissionais e estudantes de enfermagem apresentam dificuldades em lidar com a morte do paciente, pois o considera como um evento novo e distante, causando sentimentos de impotência, tristeza e medo. Destacam também a sensação de impotência que surge decorrente da formação do profissional, pois foram preparados para manter e recuperar a vida. ${ }^{(6)}$
Está implícito e embutido que o enfermeiro e técnico de enfermagem em sua formação são preparados para restaurar e salvar vidas a qualquer custo. Desta forma quando isso não é possível, ou seja, o paciente vai a óbito, estes profissionais sentem-se despreparados e vivenciam sentimentos de frustação e fracasso, pois mesmo que tenham utilizados de métodos e recursos, não foram capazes de salvar a vida do paciente. A morte do paciente não deve ser sinônimo de fracasso para o profissional de enfermagem. ${ }^{(8,10,13)} A$ morte não pode ser vista como uma doença e por isso não deve ser tratada como tal, os profissionais devem compreender como um processo natural e o paciente deve ser considerado como um ser social, com crenças e valores próprios. ${ }^{(8)}$

Fernandes ${ }^{(11)}$ em seu estudo, realizado com um grupo de técnicos de enfermagem, constatou que a morte é algo normal que faz parte da rotina dos profissionais de enfermagem, ela é entendida como alivio e descanso para o paciente, porém estes profissionais não deixam de se importar com o sofrimento do enfermo. Ressalta que a morte deve ser ocultada e reprimida quanto seja possível no ambiente hospitalar, já que há uma ideologia que o hospital é o local para a saúde e cura, não havendo espaço para a morte.

Destaca ainda, que mesmo na tentativa de se acostumar com a morte, os profissionais de enfermagem sentem dificuldade em presenciá-la, mesmo que a considerem como um acontecimento normal, pois, ao vivenciarem a morte do paciente, experimentam o medo da própria morte. ${ }^{(11)}$

Quanto maior for o vínculo afetivo entre o profissional e o paciente, maior será o grau de sofrimento e tristeza no momento da morte. O vínculo afetivo normalmente está relacionado ao tempo de permanência do paciente no hospital ou as recorrentes internações. Em algumas situações o profissional de enfermagem permite-se viver a perda e o enlutamento, pois o paciente torna-se querido para ele. Esse sentimento é tão forte para alguns profissionais, que sentem a perda do paciente como se fosse a morte de um ente querido. ${ }^{(12,14)}$ 
Como contribuição para o estudo, ressalta-se a aceitação da morte em diferentes fases da vida por parte dos profissionais de enfermagem. Estes ficam mais sensibilizados e sofrem mais quando o processo de terminalidade ocorre em crianças e pacientes jovens, isso se justifica pelo fato de que, estes em especial, não comtemplaram e viveram todas as etapas da vida, ou seja, o ciclo foi interrompido pela morte. ${ }^{(9,11,12,15)}$ Enfatiza-se que aceitação da morte em pacientes idosos é considerada como natural para os profissionais de enfermagem, pois, entende-se que faz parte do percurso natural da vida. ${ }^{(15)}$

O cuidado prestado pela enfermagem é mais especifico e melhor praticado quando o paciente é jovem, além de que, o sentimento de apego do profissional surge com maior facilidade. ${ }^{(9)} \mathrm{O}$ fato dos profissionais de enfermagem não aceitarem tão fácil a perda de um paciente jovem em relação a um idoso, pode estar relacionado/vinculado com a forma que a sociedade e nossa cultura traduz a figura do homem, sendo visto como um meio de produção e consumo. ${ }^{(1)}$

\section{CATEGORIA II - POSTURA DOS PROFISSIONAIS DE ENFERMAGEM FRENTE AO PACIENTE NO PROCESSO DA TERMINALIDADE}

Observou-se que os profissionais de enfermagem são vistos como pessoas frias e sem sentimentos pelos pacientes e seus familiares, porém, na prática isso não é verdade, já que estes profissionais sofrem ao assistirem o paciente sofrer. A dificuldade do profissional em lidar com a perda é que ele vivencia a morte do paciente como a sua própria. ${ }^{(12,1)}$

Tal comportamento em demonstrar frieza ao lidar com o enfermo sem possibilidades terapêuticas, nada mais é que um mecanismo de defesa, adotado por alguns profissionais da enfermagem para evitar o seu próprio sofrimento e facilitar o desenvolvimento de suas atividades, a maioria das vezes este sentimento é involuntário, sem o intuito de causar danos ao paciente e familiares. ${ }^{(12,1)}$
Os mecanismos de defesa mais utilizados por esses profissionais, nesta situação, são o da negação e evasão, ou seja, evitam falar sobre a morte, pois sofrem diante do sofrimento do paciente no processo de morte e sentem profundamente quando os perdem. Essa estratégia cria uma armadura para o profissional, transparecendo ser uma pessoa insensível e fria, impedindo-o seu desenvolvimento profissional e humano e como consequência interferindo negativamente nos cuidados prestados. ${ }^{(8)}$

Seguindo este pensamento os profissionais de enfermagem não estão se permitindo viver os sentimentos que envolvem o luto, talvez na tentativa de se protegerem ou por não estarem preparados emocionalmente para vivenciar tal situação. ${ }^{(14)}$ Eles acreditam que precisam manter uma postura firme e fria e que não devem conviver com o sofrimento, pois, significa romper paradigmas. ${ }^{(14)}$

Busca-se na espiritualidade e crenças religiosas, auxilio para aliviar o sofrimento dos pacientes no processo de terminalidade da vida e os seus próprios. Alguns profissionais, pacientes e familiares crêem que a vida não termina com a morte, pois se acredita que a morte é uma passagem, isto é, a matéria (corpo) morre e o espírito continua em outro plano superior. Esta percepção ajuda e torna a morte mais aceitável para os trabalhadores de enfermagem ${ }^{(11,15,12)}$

O primeiro contato com óbito é traumático, porém a vivência diária e experiência adquirida ajudam a equipe de enfermagem a terem outro olhar sobre a morte, encarando-a como um processo natural da vida o qual todos os seres humanos passarão. A perda e a tristeza permanecem, mas, essa experiência os ajuda a lidar e atuar nas situações de morte com mais humanização, oferecendo conforto para os pacientes e familiares. ${ }^{(1,8)}$

Categoria III - Implicações do preparo ou despreparo profissional da enfermagem na assistência ao paciente no processo de morte

Morte, palavra temida e impronunciável no vocabulário cotidiano, que causa questionamento, dúvida e inquietude por ser algo desconhecido. Sabe-se 
que é um fenômeno natural, entretanto, permanece sem uma definição até os dias de hoje. O processo de morte e morrer ainda causam muitas indagações e mistérios, mesmo sendo um ciclo natural da vida.

As questões que envolvem a morte dificultam a assistência prestada por alguns profissionais de enfermagem ao paciente sem possibilidades terapêuticas, essa dificuldade contribui para a valorização dos cuidados tecnicistas, de forma a cumprir protocolos e rotinas institucionais para que não haja envolvimento entre profissional e paciente. ${ }^{(17)}$

Os autores Silva, Campos e Pereira ${ }^{(17)}$ em seus estudos enfatizam a prioridade dada mais ao aparato tecnológico do que aos cuidados prestados ao paciente na sua condição de pessoa. Demonstram que é mais importante manter os equipamentos em plena funcionalidade mantendo assim o paciente vivo do que prestar um cuidado humanizado e individualizado ao enfermo. Isso comprova o quanto o profissional se distancia do paciente devido aos avanços tecnológicos que se encontram nos centros de terapia intensiva e devido também aos sentimentos, como: impotência, medo, angústia entre outros, que surge no trato com a pessoa morrente.

Os sentimentos que surgem durante a assistência ao paciente, faz com que o profissional se afaste, resultando em um cuidado não direcionado e individualizado, ou seja, o profissional assiste e monitora o paciente mecanicamente, através dos equipamentos e aparelhos, não priorizando os cuidados a nível emocional e espiritual. Este despreparo emocional impossibilita que a equipe de enfermagem observe o doente como um ser único, que necessita de conforto, amparo e cuidados especiais, mesmo que não exista possibilidade de cura. ${ }^{(17)}$

Diante de tais circunstâncias, a equipe de enfermagem, tenta justificar seu afastamento por terem que lidar com as tarefas técnicas administrativas que ocupam grande parte do seu tempo.

Todo conhecimento biológico e da tecnologia serviu para tornar o processo de morrer e morte, mas difícil de prever e lidar, aumentando o sofrimento, a angústia e as incertezas, ou seja, esse conhecimento tornou a morte um processo menos digno, prolongando o sofrimento do paciente, de seus familiares e da equipe que participa desse processo. Para alguns profissionais o fato de serem vistos como os "salvadores de vida", o mais importante é manter a vida do paciente a qualquer custo, mesmo não oferecendo uma qualidade de vida a este. ${ }^{(18)}$

Contradizendo o estudo acima, Gutierrez ${ }^{(19)}$ afirma que, a vontade do paciente deve sobrepor o investimento terapêutico e os aparatos tecnológicos, respeitando a autonomia do mesmo e minimizando seu sofrimento oferecendo conforto, atenção e uma morte digna.

Gutierrez ${ }^{(19)}$ destaca que cabe aos profissionais de enfermagem prestar os cuidados ao paciente e avaliá-los, sabendo identificar quando a cura foge aos cuidados da equipe de saúde. Nesses casos resta somente proporcionar os cuidados paliativos, seguindo o principio da assistência humanizada, tornando o processo de terminalidade humano, menos doloroso, tanto para o paciente quanto para seus familiares.

\section{DISCUSSÃO}

Entende-se que a essência da enfermagem é cuidar de gente à luz de uma assistência humanizada, através da promoção em saúde, recuperação/ reabilitação do paciente ao seu convívio social. Quando o profissional se depara com uma situação diferente da habitual e que os cuidados prestados são apenas para proporcionar ao enfermo uma morte digna, nesse momento o profissional entra em conflito com ele próprio, pois, tal situação vai de encontro com o seu preparo acadêmico/profissional e psicológico.

Nota-se que durante o processo de formação e na vivência acadêmica, são poucas ou pode-se dizer nenhuma, as oportunidades para se falar sobre a morte e/ou o contato com paciente no processo de terminalidade, tais situações contribuem para o 
despreparo emocional e o emprego de estratégias de defesa diante da morte, que quase sempre tende ao distanciamento do paciente e familiar, implicando na assistência prestada.

$\mathrm{Na}$ sua rotina diária o profissional de enfermagem que lida com o enfermo sem possibilidades terapêuticas medicamentosas, "carrega" sentimentos de frustração, impotência, tristeza, raiva, entre outros, que dificultam sua relação profissional com o paciente/familiar. Tais sentimentos são omitidos e contidos no ambiente de trabalho, ou seja, alguns colaboradores de enfermagem não se permitem expressar e vivenciar o luto. Percebemos também que para alguns profissionais a morte é aceita de forma tranquila, pois faz parte do ciclo da vida. Entretanto, quando o paciente é criança ou jovem, fica mais difícil aceitá-la, em relação a um paciente idoso.

\begin{abstract}
Kubler-Ross expressa que a aflição, a vergonha, a culpa são sentimentos que não se diferenciam muito da raiva e da fúria. Como ninguém gosta de admitir sentimentos de raiva por uma pessoa falecida, estas emoções são, no mais das vezes, disfarçadas ou reprimidas, delongando o período de pesar ou se revelando por outras maneiras. (3)
\end{abstract}

Para enfrentar todo o processo de morrer e morte, determinados profissionais tendem a adquirir uma postura que muitas vezes é vista pelo paciente/família como insensível e fria. Tal postura, nada mais é do que uma estratégia de defesa ou fuga para se manter afastado, evitando um sofrimento futuro. Outros profissionais buscam na religião o entendimento para compreender e aceitar a morte, diante do exposto, lidar com o processo de terminalidade se torna menos penoso e árduo. O distanciamento é rompido e os cuidados prestados deixam de ser tecnicistas, e passam a ter mais atenção, afeto, um olhar e um toque carinhoso, o saber ouvir e respeitar os desejos do cliente.

É de grande importância que as instituições hospitalares criem grupos multidisciplinares para discutir e debater sobre a morte e todo o seu processo, permitindo aos profissionais da enfermagem e aos membros da equipe de saúde expor suas dificuldades, sentimentos, dúvidas e experiências que vivenciam ao lidar com o paciente terminal. Desta forma, busca-se que os trabalhadores da enfermagem tenham um entendimento e uma compressão a respeito da morte, reduzindo e minimizando as angústias e desgastes emocional/psicológico, favorecendo uma melhoria na qualidade da assistência prestada.

\section{CONSIDERAÇÕES FINAIS}

Como foi exposto na pesquisa, a temática morte quase nunca é discutida durante a formação acadêmica. Durante a graduação e os estágios realizados, não tivemos a oportunidade de vivenciar a prática da assistência diante do processo de terminalidade mais profundamente, o que justifica a insegurança e medo ao se deparar com um paciente morrente. Ao considerar a importância desse aprendizado ainda na academia, as instituições de ensino deveriam incitar no seu currículo mais discussões acerca desta temática ao longo das disciplinas, a fim de preparar os acadêmicos de enfermagem a lidar com esses sentimentos que emergem na pratica do cuidar de um ser humano no seu processo natural de vida.

Observamos que além do estresse que está relacionado ao excesso de atividades e demandas, o trabalhador da enfermagem precisa saber lidar com o estresse emocional que está relacionado com a morte do paciente, para o qual não está preparado, refletindo na qualidade dos cuidados e na sua estrutura psicológica.

Podemos concluir que esse estudo agregou valores positivos para a nossa vida pessoal, mas principalmente para nossa vida profissional. Como futuras profissionais de enfermagem, passaremos a observar o paciente terminal na sua totalidade, como um ser que precisa não somente dos apareIhos e drogas para se manter vivo, mais em essencial de cuidados que proporcionem conforto para o corpo e para a alma, pois, as ações devem estar voltadas para o cuidado de qualidade e humanizado, durante e após a morte do paciente. 


\section{REFERÊNCIAS}

1. Rosa AF, Lunardi VL, Barlem ED, Filho WDL. Percepções das enfermeiras frente aos sentimentos de quem vivência o processo de morrer e morte. Ciênc. Cuid. Saúde. 2006;5(2):204-211.

2. Kovasc MJ. Cuidando do cuidador profissional. In: Oliveira RA et al. Cuidado paliativo. São Paulo: CREMESP; 2008. p. 91-92.

3. Ross EK. Sobre o temor da morte. In: Ross EK. Sobre a morte e o morrer. São Paulo: Martins Fonte; 1996. p. 20.

4. Smeltzer SC, Bare BG. Brunner \& Suddarth: tratado de enfermagem médico-cirúrgica. $10^{a}$ ed. Rio de Janeiro: Guanabara Koogan; $2 \mathrm{Ol2}$.

5. Prearo C, Gonçalves LS, Vinhando MB, Menezes SL. Percepção do enfermeiro sobre o cuidado prestado aos pacientes portadores de neoplasia. Ciênc saúde. 2011;18(1):20-7.

6. Oliveira WIA, Amorim RC. A morte e o morrer no processo de formação do enfermeiro. Rev. gauch. enferm. 2008;29(2):191-8.

7. Sulzbacher M, Reck AV, Stumm EMF, Hildebrandt LM. O enfermeiro em unidade de tratamento intensivo vivenciando e enfrentando situações de morte e morrer. Sci med. 2009; 19(1)11-16.

8. Mota MS, Gomes GC, Coelho MF, Lunardi Filho WD, Souza LD. Reações e sentimentos e profissionais da enfermagem frente à morte dos pacientes sob seus cuidados. Rev. gauch. enferm. 2011;32(1):129-35.

9. Silva ALL, Ruiz EM. Cuidar, morte e morrer: significações para profissionais de enfermagem. Estud. psicol. (Campinas). 2003; 2O(1):15-25.

1O. Borges MS, Mendes N. Representações de profissionais de saúde sobre a morte e o processo de morrer. Rev. bras. enferm. 2012;65(2):324-31.
11. Fernandes PV, Iglesias A, Avellar LZ. O técnico de enfermagem diante da morte: concepções de morte para técnicos de enfermagem em oncologia e suas implicações na rotina de trabalho e na vida cotidiana. Psicol. teor. prát. 2009;11(1):142-152.

12. Shimizu HE. Como os trabalhadores de enfermagem enfrentam o processo de morrer. Rev bras. enferm. 2007;60(3):257-62.

13. Faria DAP, Maia EMC. Ansiedades e sentimentos de profissionais da enfermagem nas situações de terminalidade em oncologia. Rev latinoam enferm. 2007;15(6).

14. Costa JC, Lima RAG. Luto da equipe: revelações dos profissionais de enfermagem sobre o cuidado a criança/adolescente no processo de morte e morrer. Rev. latinoam enferm. 2005; 13(2):151-7.

15. Medeiros YKF, Bonfada D. Refletindo sobre finitude: um enfoque na assistência de enfermagem frente à terminalidade. Rev. RENE. 2012;13(4):845-52.

16. Gutierrez BAO, Ciampone MHT. O processo de morrer e a morte no enfoque dos profissionais de enfermagem de UTIs. Rev. Esc. Enferm. USP. 2007;41(4)660-7.

17. Silva RS, Campos ERA, Pereira A. Cuidando do paciente no processo de morte na unidade de terapia intensiva. Rev. Esc. Enferm. USP. 2011;45(3):738-44.

18. Sanches PG, Carvalho MDB. Vivência dos enfermeiros de unidade de terapia intensiva frente á morte e o morrer. Rev. gauch. enferm. 2009; 30(2): 289-96.

19. Gutierrez BAO, Ciampone MHT. Profissionais de enfermagem frente ao processo de morte em unidades de terapia intensiva. Acta paul. enferm. 2006;19(4):456-61. 